\title{
Vascular system of the optic nerve head and retina in the pig
}

\section{J. ROOTMAN*}

From the Department of Pathology, Institute of Ophthalmology, University of London

Several investigators have recently used the pig (Suidae) as an experimental model in the $-\vec{\circ}$ study of the retinal vasculature (Ashton, Dollery, Henkind, Hill, Paterson, Ramalho, and $\vec{\rho}$ Shakib, 1966; Dollery, Henkind, Paterson, Ramalho, and Hill, 1965; Dollery, Henkind,o․ㅡ. Kohner, and Paterson, I 968; Kohner, Dollery, Henkind, Paterson, and Ramalho, I $967 ; 0$ Kohner, Dollery, Shakib, Henkind, Paterson, de Oliveira, and Bulpitt, I970; Henkind and Dollery, 1966). The retinal circulation in the pig is holangiotic and is said to resemble closely that of man (Bloodworth, Gutgesell, and Engerman, I965; Duke-Elder, 1958; Langenbacher, I880). Most of the literature available on this subject either con-음 cerns a single aspect of the microcirculation or is confusing. It was felt that a reinvestigation of the retinal vasculature system would be of interest to experimentalists using the pig as a laboratory animal.

It is important at the outset to understand the origin of the orbital blood supply in the pig. As is common in the lower mammalia, the major orbital supply is derived from the external carotid circulation via the external ophthalmic artery (Duke-Elder, I958; Prin@ Diesem, Eglitis, and Ruskell, I960). The internal carotid is almost vestigial and tecerebral circulation, arising from a carotid rete derived from the ascending pharynge artery, makes a minor contribution via the internal ophthalmic artery (Daniel, Dawes, and Pritchard, I953). The retinal arteries arise from the main ciliary vessels and pierce theg sclera around the optic nerve head. Retinal veins come out through scleral channels to join the posterior ciliary veins (Prince and others, i960).

\section{Materials and methods}

The retinae examined were obtained from seven pigs in their first week of life and two at 3 months of age. Direct ophthalmoscopy was carried out under phenobarbital anaesthesia with completeं mydriasis. Animals were injected with Indian ink by either the intraventricular or the intracarotid 3 . route as described by Ashton, Ward, and Serpell (1954) and Ashton and others (1966). Upon im-ô mediate enucleation the eyes were placed in ro per cent. formol saline, and fixed for 24 hours. The 3 anterior segment was removed and the vessels were examined in situ by means of a binocular dis-음 secting microscope. Globes were oriented with pre-placed superior limbal sutures. After extirpat- $\rightarrow$ ion of the vitreous the retinae and remaining parts of the ciliary bodies were dissected free of the choroid and sclera. The retinae were incised radially, laid flat on glass slides, and gently mounted in warm 30 per cent. glycerin. One retina, after examination and photography, was cut by hand intothin sections which were laid on their sides and examined. Several eyes, sectioned equatorially, bleached with potassium permanganate and oxalic acid, and cleared with glycerin, were examined $\omega$ in situ and after removal of the scleral coat. Globes from two animals were embedded in paraffin for histological study. Sections were stained with haematoxylin and eosin, with PTAH, and by silver? impregnation for nerve fibres. Several retinae were digested by the pepsin trypsin technique (Ashton, 1963) and stained with PAS and haematoxylin. 


\section{Results}

In vivo OBSERVATION

The fundus of the pig lacks a tapetum (Lindsay Johnson, I90 I ; Prince and others, I96o), and its colour varies from red-brown to grey, depending upon the amount of pigmentation. Three or four major arteries and several smaller vessels arise from the periphery of the inferiorly placed oval disc, the accompanying veins draining more centrally. Arteries emanating from the papilla as isolated channels often bifurcate near the disc while some veins are seen to anastomose close to the disc margin (Fig. I). The normal arteriovenous ratio is three to two. The vascular pattern is as described by Bruns (1882) with superior and inferior temporal and nasal vessels. By direct ophthalmoscopy and in photographs in the literature (Ashton and others, I966), the major vessels are seen to cast a shadow on the retinal surface and hence appear to lie superficially (Fig. 2). In contrast to previous reports (François and Neetens, I 962; Michaelson, I 954; Prince and others, I960), the present study indicates that at crossings veins generally lie over the arteries, although the opposite also occurs. Arterial and venous branching is both dichotomous and bisular (side arm), the latter prevailing on the arterial side. An area corresponding to a macula is not noted on ophthalmoscopy.

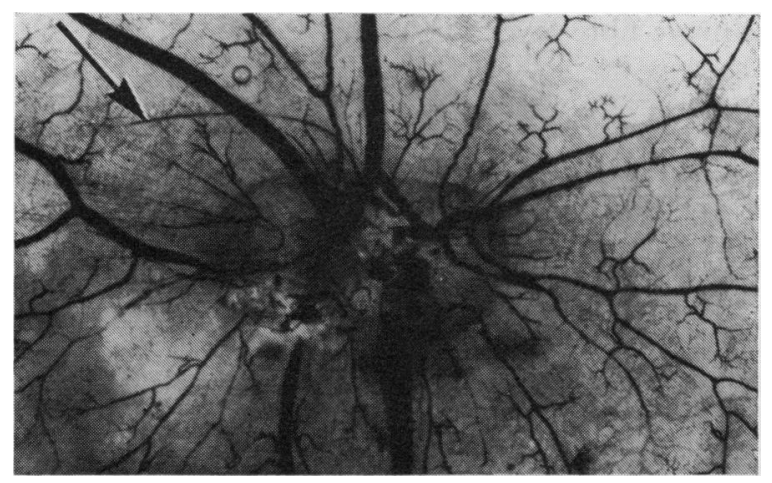

FIG. I Pig. 2 Indian ink injection of disc and peripapillary area. Note bifurcatoin of arterial channels and anastomosis of venous channels near disc. Bisular branching of arterioles is evident as is the hyaloid artery (arrow). $\quad \times 13$

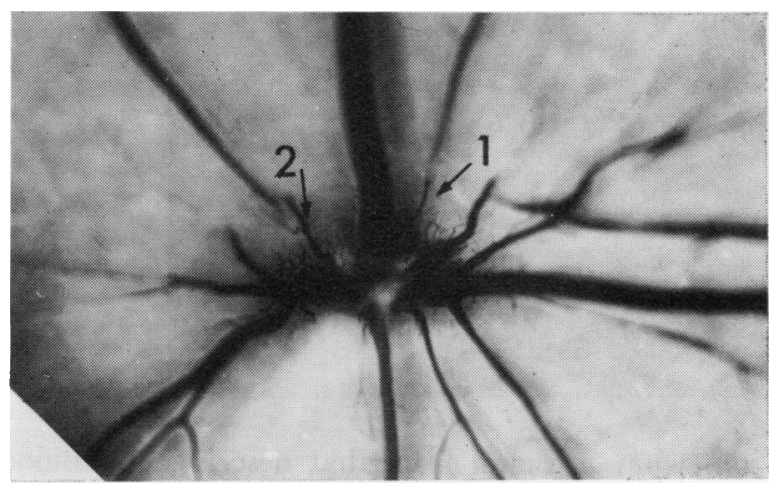

FIG. 2 Pig 5a. Indian ink infection of optic disc area photographed in situ. Note smaller venous channels draining into large vessels (arrows I and 2) of nerve head. Larger vessels cast a shadow upon the retina. $\quad \times 13$

HISTOLOGICAL AND THIN SPECIMENS

The retinal vessels are seen to penetrate the sclera about the optic nerve with the occasional vessel branching at the disc to enter the choroid and the retina. There is no central retinal artery, and fine capillaries are evident within the optic nerve head overlying the 
lamina cribrosa. The larger vessels lie close to the internal limiting membrane bulging into the vitreous; however, as suggested by Bruns (1882) and Bloodworth and others (I965), they are truly within the nerve fibre layer (Fig. 3). A single adventitial coat is noted at arterio-venous crossings.

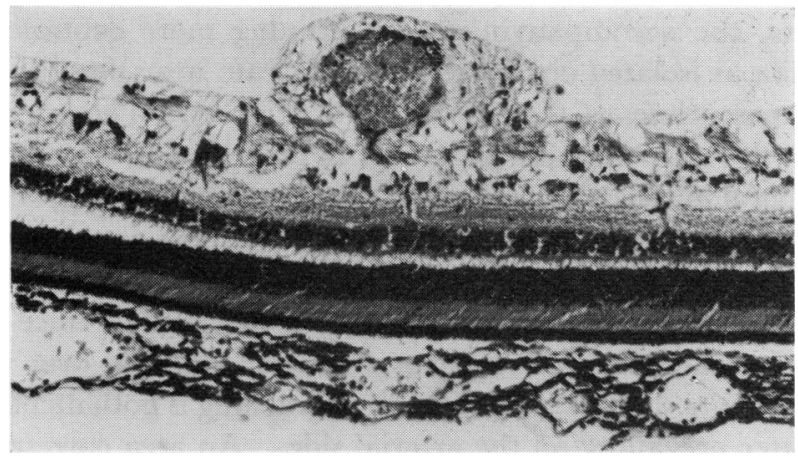

FIG. 3 Pig. 9 Larger vessel lying close to internal limiting membrane and bulging into vitreous. Haematoxylin and eosin. $\times 115$

In the immediate peripapillary area, four capillary layers are noted (Fig. 4):

(a) Superficially within the nerve fibre layer;

(b) In the ganglion cell layer;

(c) In the middle of the outer plexiform layer;

(d) At the union of the inner two-thirds and outer one-third of the inner molecular layer.

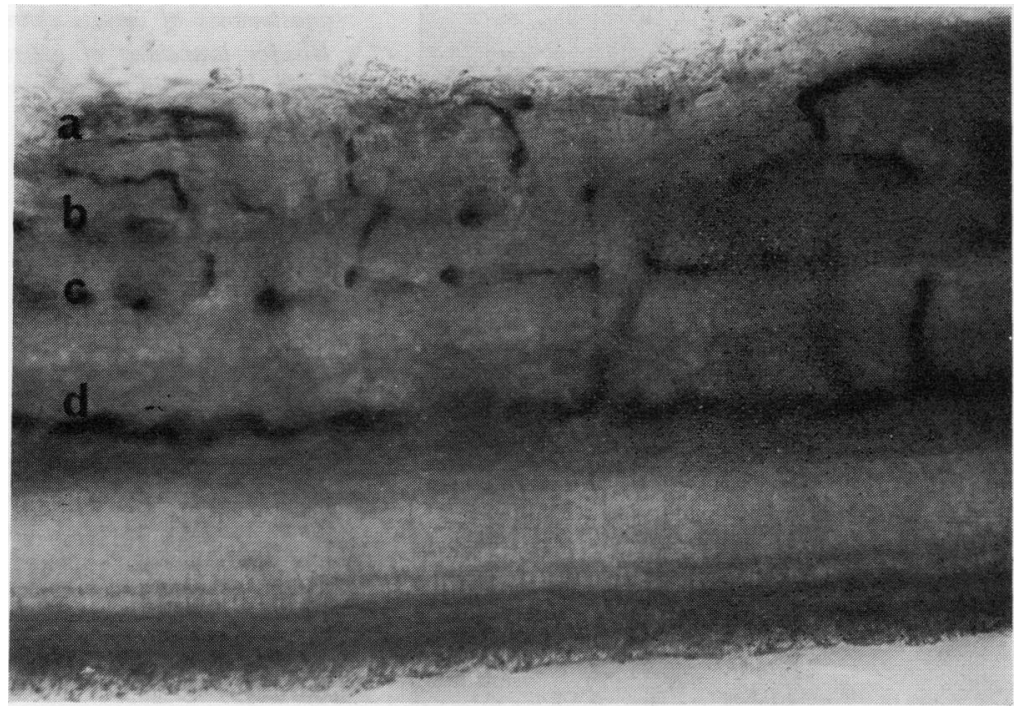

FIG. 4 Pig 5. Immediate peripapillary area. Four capillary layers are evident $(a, \quad b, \quad c, \quad d)$. Indian ink ininjected thin sections viewed coronally. $\times 308$

This distribution differs somewhat in detail from that described by Bloodworth and others ( 1965$)$. Towards the equatorial region only three distinct layers are evident, the most superficial having become attenuated (Fig. 5, opposite). Nearer the periphery the capillary nets tend to merge, particularly those within the ganglion cell and inner plexiform layers. Several sections showed a large thin-walled peripheral venous channel adjacent to the ora ciliaris retinae (Fig. 6, opposite). 


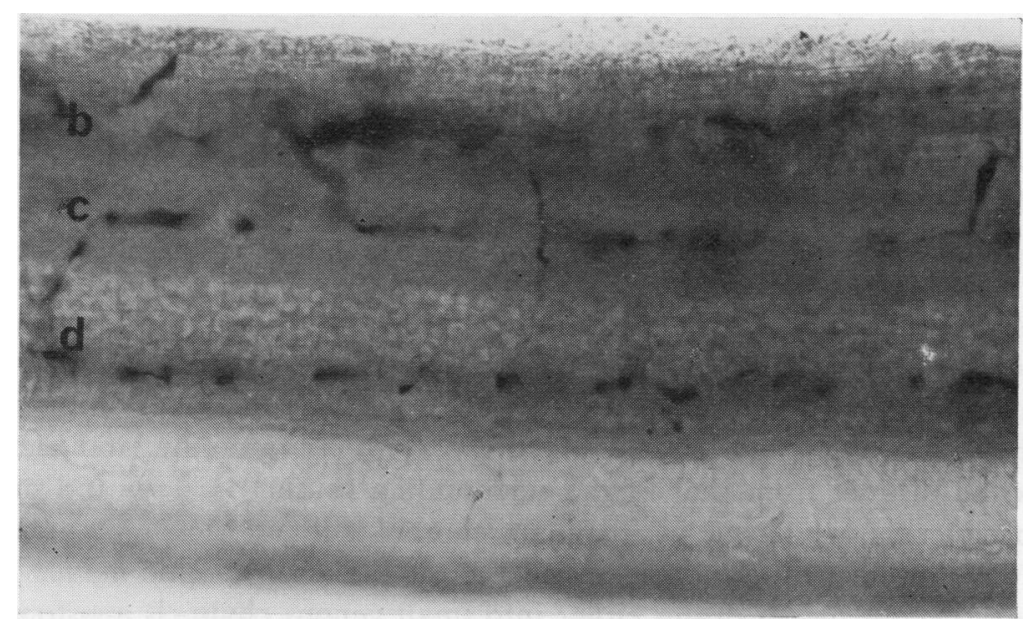

FIG. 5 Pig 5. In the equatorial region only three layers are now distinct $(b, c, d)$. $\times 308$

FIG. 6 Pig I. Thin-walled peripheral venous channel (arrow). Haematoxylin and eosin. $\times 126$

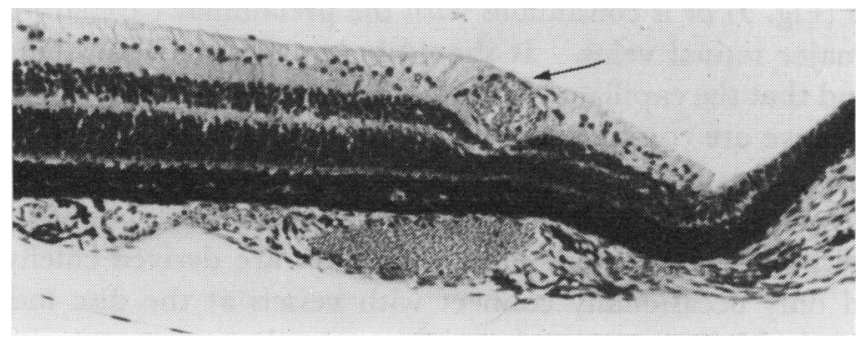

\section{INJEGTED SPEGIMENS}

In many of the young animals remnants of the hyaloid system are present at the disc and extend forward as a hyaloid artery to anastomose with a prominent tunica vasculosa lentis. The tunica is not present in the animals at 3 months of age.

DISG AND PERIPAPILLARY AREA

Specimens of the optic nerve head and surrounding sclera cleared by a modified Spalteholz technique show a distinct circle of Zinn-Haller previously noted by Bruns (1882) (Fig. 7).

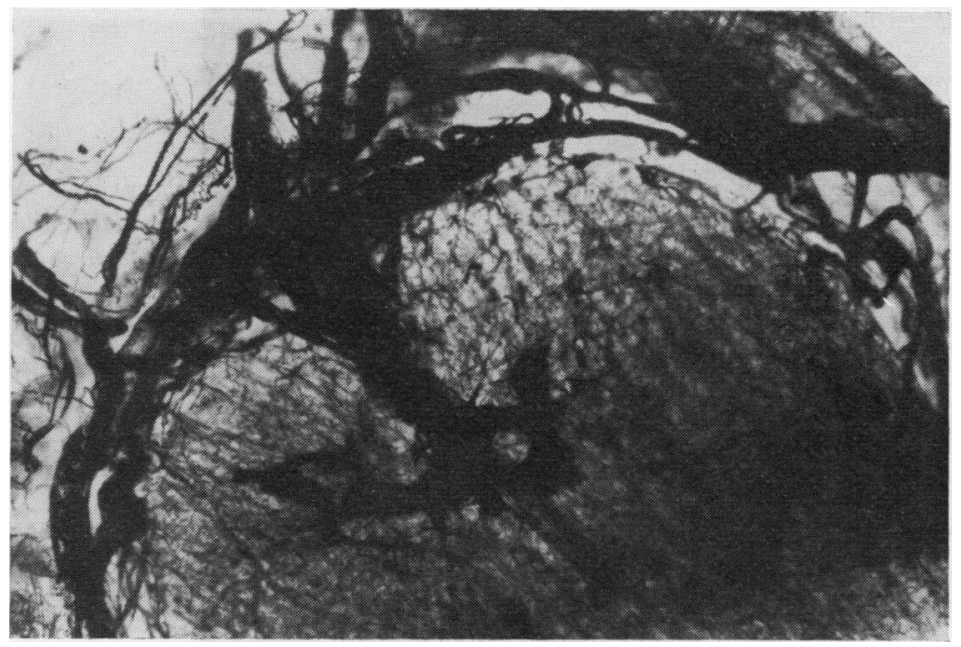

FIG. 7 Pig 3. Left optic nerve head cleared by modified Spalteholz technique. Note distinct arterial circle of Zinn-Haller. $\quad \times 18$ 
Vessels arising from the circle of Zinn-Haller are distributed in the following manner:

(I) As recurrent branches anastomosing with the rich plexus of vessels of the pial sheath;

(2) As branches anastomosing with the capillary nets of the lamina cribrosa and the retro- and pre-laminar nerve head;

(3) As some of the smaller vessels supplying the immediate peripapillary area.

The dense capillary nets supplying the nerve head and peripapillary zone arise from branches of the circle of Zinn-Haller as well as from separate smaller channels penetrating the sclera around the optic nerve head. These observations support the angiographic studies which have suggested that the blood supply of the optic disc and immediate area appears to be distinct from that of the surrounding retina (Dollery and others, 1968). Several specimens in which the peripapillary choroid is intact show an anastomosis of the vessels of the choroid with the capillary nets of the prelaminar optic nerve. The deeper peripapillary venous plexus drains either into small venous channels anastomosing at the disc with larger veins (Fig. 2) or is continuous with the prelaminar capillary plexus which in turn drains into major retinal veins. It should be noted that individual variation of blood supply exists and that the capillary nets of the retrolaminar and laminar as well as of the prelaminar optic nerve are continuous.

A distinctive radial peripapillary net, as described by Henkind ( $1967 a, b)$, is most evident superiorly as well as nasally and temporally. This study supports observations made by Dollery and others (1968) that these capillaries are derived chiefly from intraretinal arterioles and only occasionally connect with vessels at the disc margin. They pursue a relatively long straight course undergoing repeated anastomoses with underlying arterioles (Fig. 8). Ultimately these vessels join the underlying capillary nets in the nerve fibre layer. This differs from the human counterpart wherein these vessels are said to anas tomose directly with underlying venules (Henkind, I967a). Injected specimens confirmed observations made in vivo with regard to vessel size, arterio-venous crossings, and type of branching.

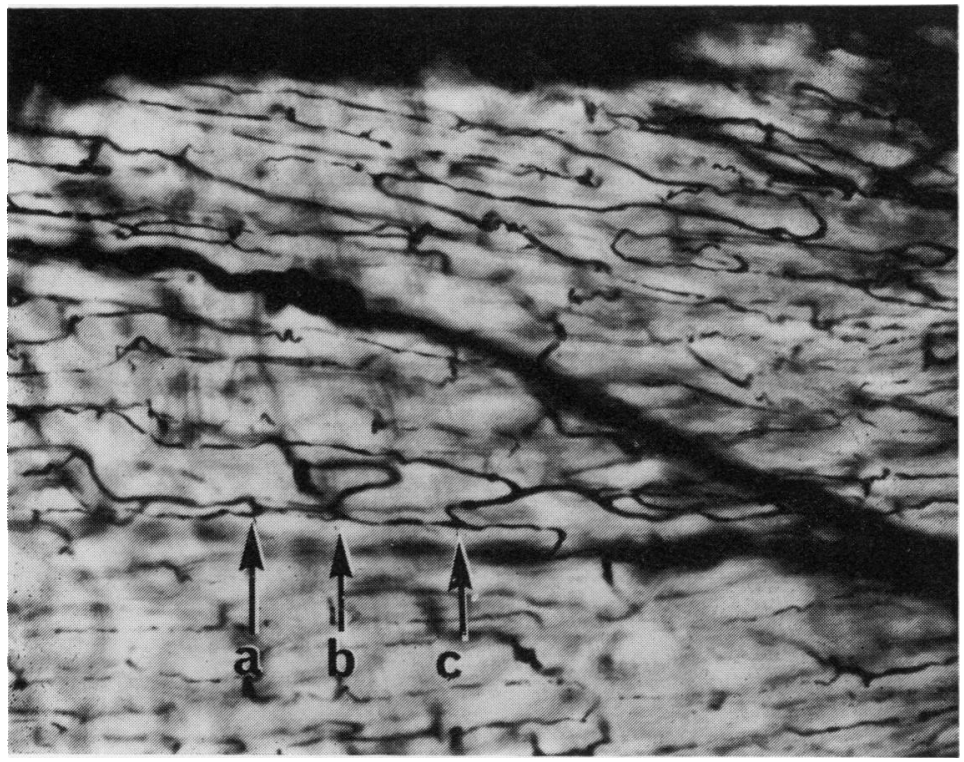

FIG. 8 Pig 2. Radial peripapillary capillaries undergo repeated anastomoses with underlying arterioles (arrows $a, b$, c). $\times 13^{8}$ 


\section{REMAINDER OF FUNDUS}

Superimposition of territories of major arterial and venous channels is rare. An obvious feature, characteristic of a number of mammalia (Bruns, 1882; Prince and others, 1960), is the large venous channel that extends throughout the temporal periphery immediately adjacent to the ora ciliaris retinae (Fig. 9). These vessels arise from veins extending peripherally towards them and are seen to drain into the inferior nasal, inferior temporal, and (occasionally) into the superior temporal veins. Vein endings of this so called, "circulus venosus anterior" (Bruns, 1882) never anastomose directly but may do so through terminal capillary nets. The remainder of the periphery is supplied by loose-meshed capillary nets extending between both arterial and venous channels.

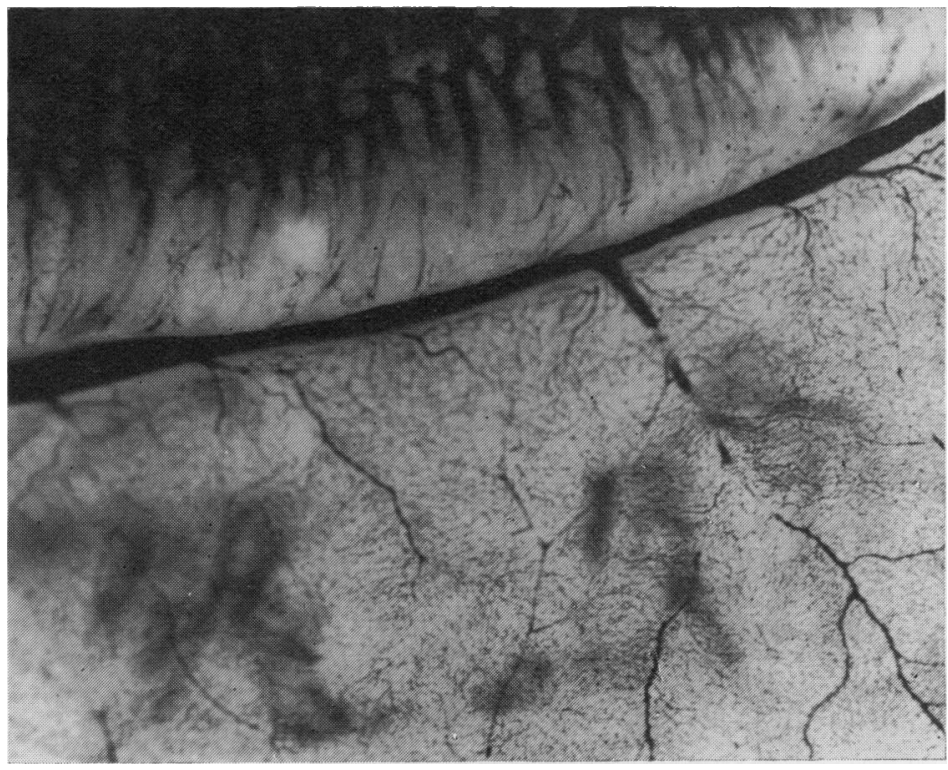

FIG. 9 Pig 5a. Indian ink injection with pigmented ciliary epithelium bleached. The large peripheral venous channel is striking. $\times 18$

A specimen in which the pigment epithelium of the ciliary body had been removed revealed an unusual and, to our knowledge, unique observation. Occasional arteriolar and capillary size channels extend superficially across the ora ciliaris to lie on the ciliary body (Fig. 10). Bleached specimens confirmed this observation and indicated that such channels are rare, are seen only in the younger animals, and appear attenuated, often injecting incompletely. These channels have no connection with the ciliary circulation. Occasional islands of retinal tissue were also seen to extend on to the ciliary body, a feature noted commonly in man (Duke-Elder, 1964).

A capillary-free area suggesting macular function is not evident in our specimens. This finding is in accord with that noted by Bloodworth and others ( 1965 ) and is contrary to the suggestion by Prince and others (1960) that an area centralis exists supero-temporal to the disc. However, a broad zone, supplied by capillaries alone, extends across the horizontal axis of the retina (Fig. I $1 a$ ). The only major vessels crossing this zone are those supplying and draining the superior sector. Coronal and sagittal serial sections through this zone and the remainder of the fundus show a general tendency to an increased ganglion cell population superior to the disc in this area, most clearly shown in specimens embedded in celloidin where structural relationships are maintained (Fig. I $1 b$ ). 


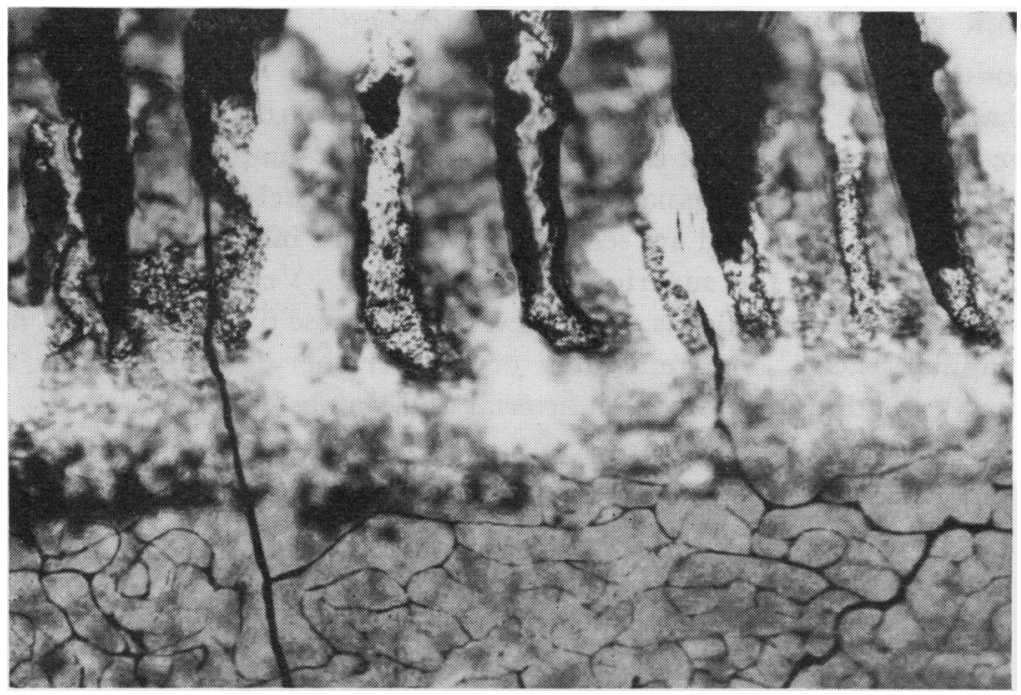

FIG. IO Pig 2 Vascular channels extending superficially across the ora ciliaris. $\times 62$

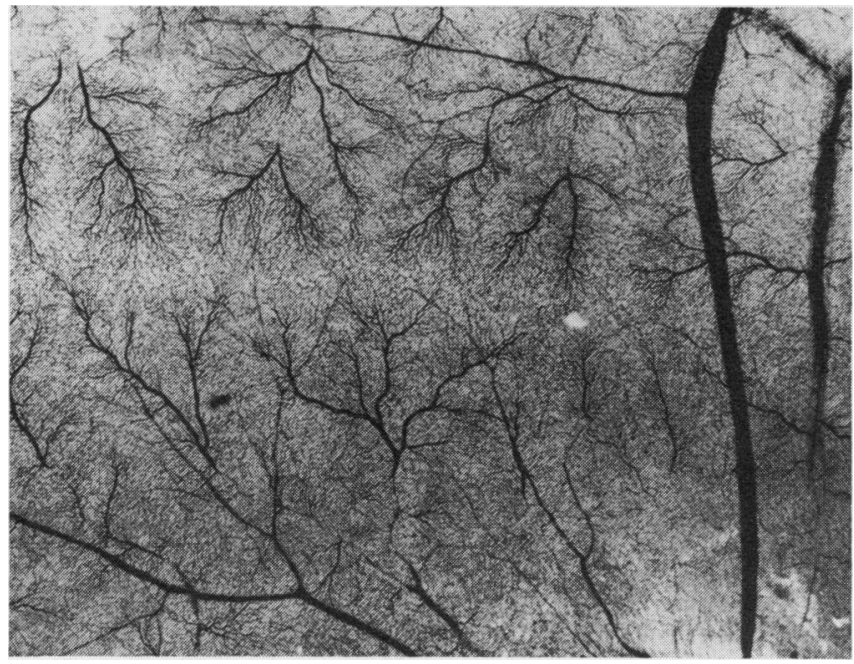

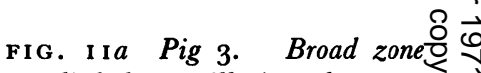
supplied by capillaries alone extending horizontally across superior pole. $\times 18$

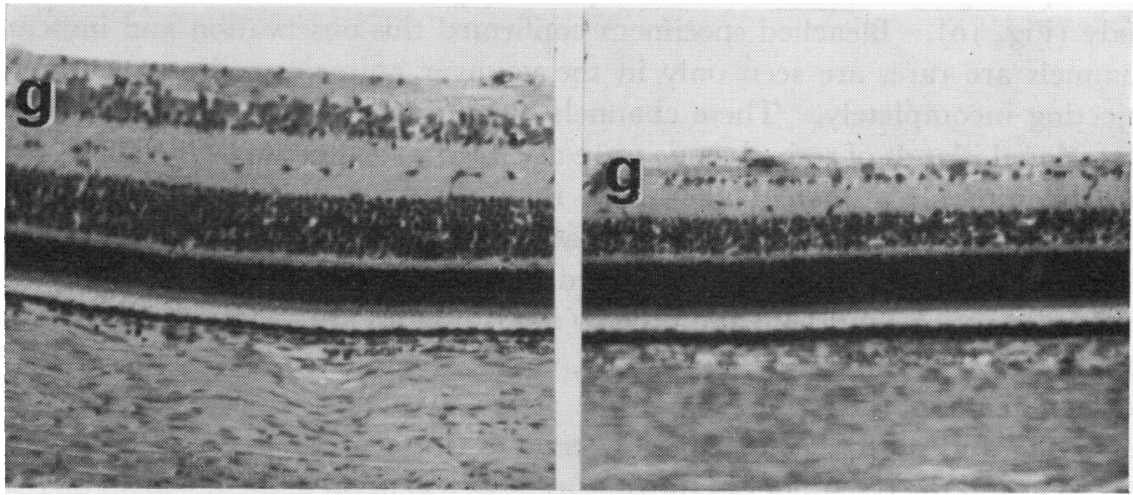

FIG. I I $b$ Pig I. Sections of the retina demonstrating increased ganglion cell population $(g)$ of the horizontal zone supplied by capillaries alone (left), compared to a zone equidistant below the disc (right). Celloidin embedded. Haematoxylin and eosin. $\times 168$ 
Schultze ( 1892 ) and Bloodworth and others (1965) have described a capillary-free zone about the arteries in the pig, while Henkind and de Oliveira (1967) have thrown some doubt on its existence. The present study supports the existence of such a zone, although it is less evident in the pig compared to other species. The reason for a less obvious capillary-free zone is two-fold.

(a) Since the major vessels lie very superficially within the retina (Fig. 3), often bulging into the vitreous, the zone exists only as a concavity beneath the vessel where it comes into relation with a capillary bed;

(b) Arteriolar channels arising from these major vessels are not only superficial and short but, by virtue of their size, have a narrow capillary-free zone.

Bruns (1882) was struck by the peculiar propensity for large venous channels to form deep within the inner molecular layer and to ascend rather abruptly to drain into major veins. He also suggested that the arterioles ramify chiefly within the ganglion cell and outer plexiform layers. In essence, this study is in accord with these observations. Several new findings, however, must be added. As the venous channels ascend, often in a stepwise fashion, they collect vessels from the capillary nets within each layer (Figs I 2 and I 3 ).

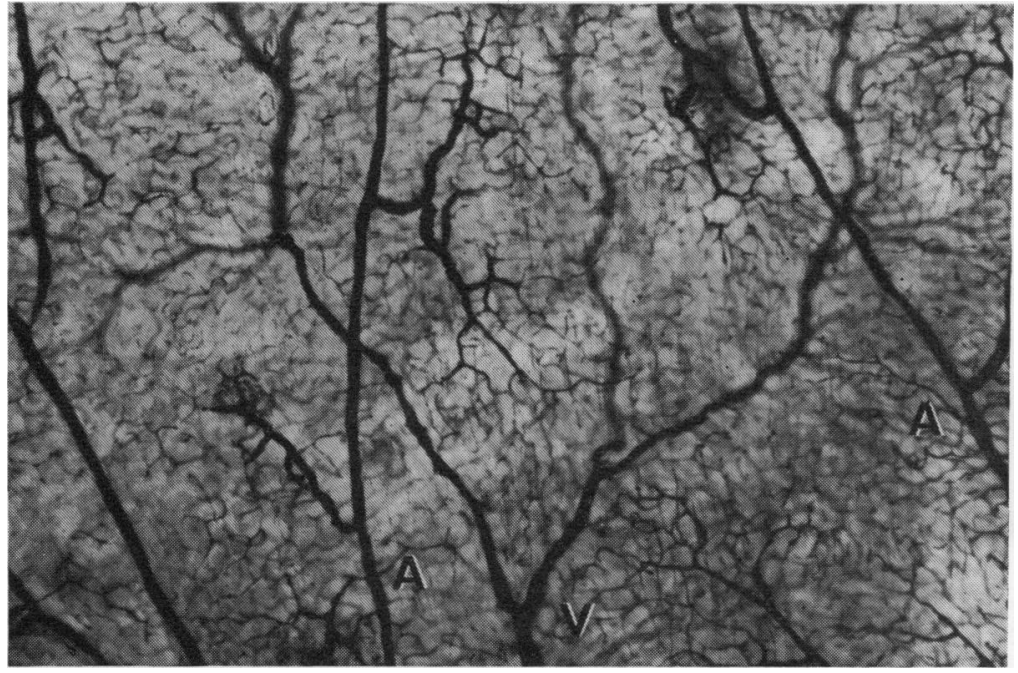

FIG. I2 Pig 2 Venous channel (V) flanked by arterioles $(A)$. Photographed in the superficial layers. Note arterioles and only part of venule in focus. $\times 62$

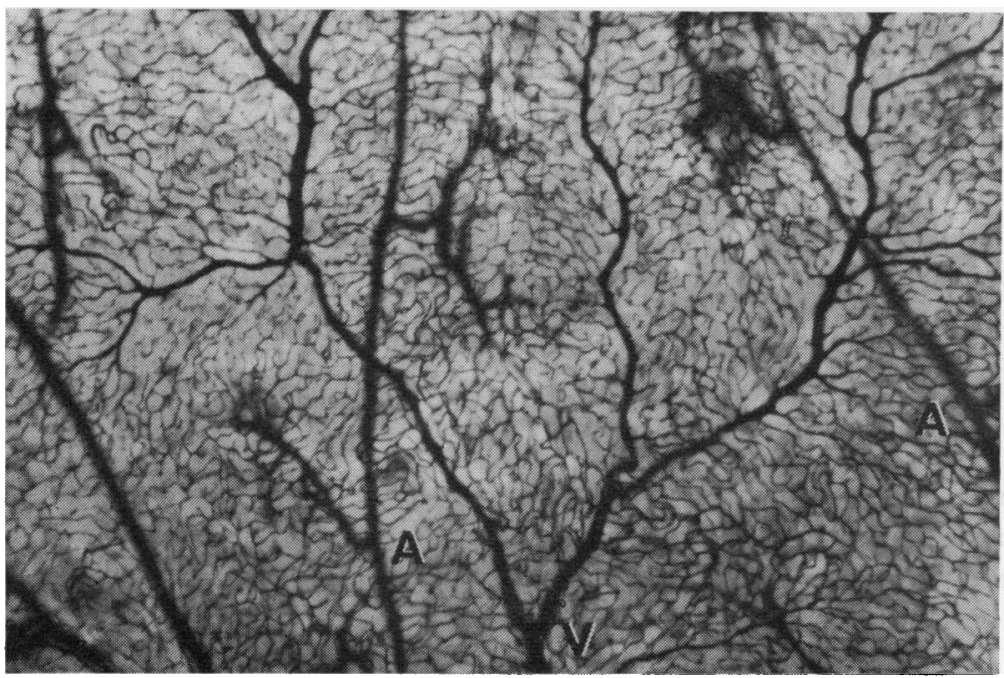

FIg. I3 Pig 2. Same area as Fig. I 2 photographed at level of venous layer. Note arterioles $(A)$ are now out of focus. $\times 62$ 
For the most part the arterioles form capillary nets within the superficial layers and these, in turn, communicate with those in the inner molecular layer (Fig. I4). However, thin sections of the injected specimens viewed coronally revealed a number of vessels of arteriolar size that appear to connect with the capillary nets of all three layers (Fig. 15). This is not as obvious a feature as the communication of the venous channels within all layers. Fig. I6 (opposite) is an artist's drawing of a conceptual model of the circulation within the pig retina as outlined in this study.

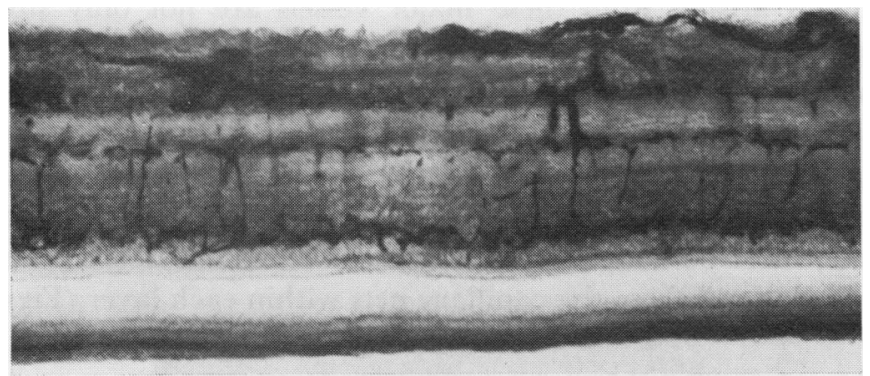

FIG. 14 Pig 5. Indian ink injection viewed coronally. Note arterioles form capillary nets in superficial layers which in turn communicate with those in the inner molecular layer. $\times 138$

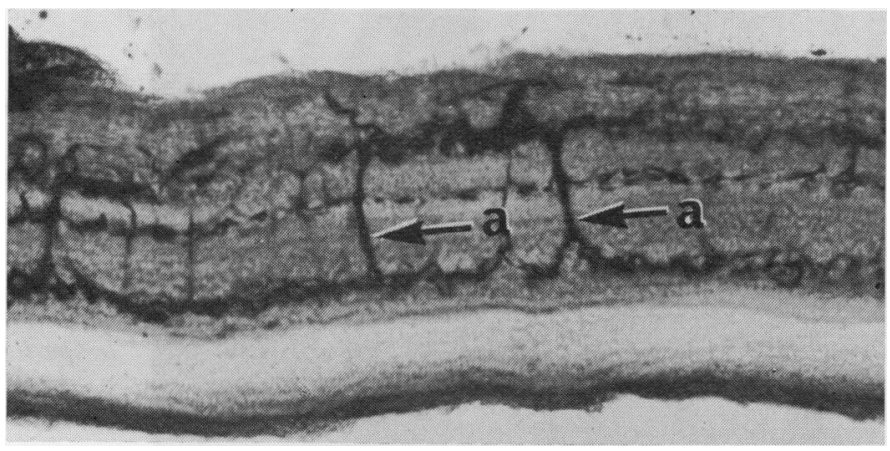

F I G. I 5 Pig 5. Note several arteriolar-sized channels (a) communicating with capillary nets of all three layers. $\quad \times 13^{8}$

Bruns (1882) described the capillary network as rather narrow, polygonally arranged, and with a maximum net size of $33 \mu$ and a minimum of $22 \mu$. In the present study capillary net size is measured from representative photographs at magnifications of $175 \times$. Fields selected are in the plane of the intermediate and deeper capillary layers and midway between either arterial or venous channels. Measurements are taken in the horizontal and vertical axis at $4 \mathrm{~mm}$. and $8 \mathrm{~mm}$. from the centre of the papilla. The results are set out in the Table (p. 8r 7 ).

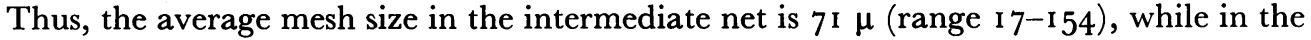
deeper layer the average mesh size is $48 \mu$ (range I I-I 54). Generally, the mesh size in both the deeper and the intermediate layer tends to be greater as the retinal periphery is approached.

\section{RETINAL DIGESTS}

The vascular plexus in the digests appears to be particularly dense with the collapse and superimposition of capillary networks. Arterial elements are more cellular and stain more intensely than do veins. Capillaries are of uniform size and are lined by endothelial cells with pericytes incorporated in the vessel walls. In several areas capillary retraction is evident though not prominent. Although not a striking feature, PAS-positive material 


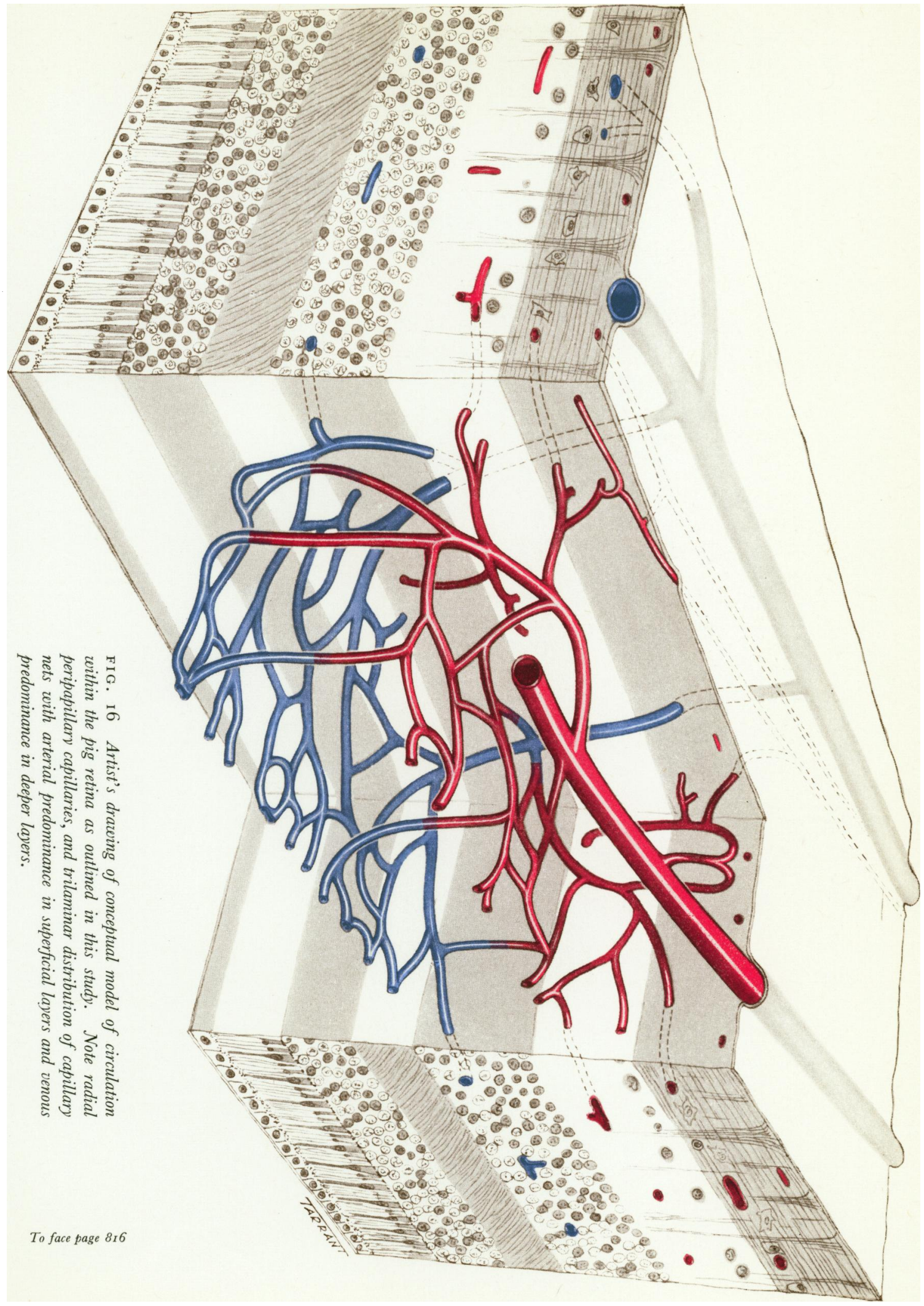


Table Lengths and widths of capillary nets of the intermediate and deep vascular layers

\begin{tabular}{|c|c|c|c|c|c|c|c|c|c|}
\hline \multirow{3}{*}{ Layer } & & \multicolumn{4}{|c|}{ Intermediate } & \multicolumn{4}{|l|}{ Deep } \\
\hline & & \multicolumn{2}{|c|}{ Length $(\mu)$} & \multicolumn{2}{|c|}{ Width $(\mu)$} & \multicolumn{2}{|c|}{ Length $(\mu)$} & \multicolumn{2}{|c|}{ Width $(\mu)$} \\
\hline & & Average & Range & Average & Range & Average & Range & Average & Range \\
\hline \multirow{8}{*}{$\begin{array}{l}\text { Area } \\
\text { examined }\end{array}$} & $4 \mathrm{~mm}$. Nasal & 120 & $8 I-171$ & $4^{2}$ & $29-51$ & 64 & $45^{-80}$ & 29 & $23-40$ \\
\hline & Temporal & $9^{1}$ & $71-144$ & 34 & $29-45$ & 54 & $45-80$ & 25 & $17-29$ \\
\hline & Superior & 94 & $57-143$ & 33 & $29-45$ & 63 & $34-80$ & 25 & $17-34$ \\
\hline & Inferior & 100 & $80-143$ & 39 & $29-57$ & 53 & $29-86$ & 26 & $23-45$ \\
\hline & $8 \mathrm{~mm}$. Nasal & 116 & I09-I 54 & 30 & $17-40$ & 83 & $29-114$ & 35 & $23-45$ \\
\hline & Temporal & 119 & $\overline{97-137}$ & $3 I$ & $23-40$ & 94 & $4^{0-1} 54$ & 23 & I I -29 \\
\hline & Superior & 105 & $69-143$ & 37 & $23-45$ & $7^{2}$ & $23-114$ & $2 \mathrm{I}$ & I $1-29$ \\
\hline & Inferior & 112 & $\overline{57-137}$ & 40 & $29-57$ & 71 & $\overline{34-109}$ & 32 & $17-40$ \\
\hline
\end{tabular}

is present at the site of bisular branching of arterioles, particularly in the posterior pole. Henkind and de Oliveira (1968) previously noted this in the pig and considered it to be evidence of arteriolar annuli.

\section{Discussion}

Although the retinal circulation in the pig is holangiotic and bears some resemblance to that of man, several distinct differences exist:

(I) The orbital circulation takes origin from the external carotid system via the external ophthalmic artery which has a particularly long extraorbital course in this species (Prince and others, 1960). In contrast to the internal carotid circulation, this system is subject to major alterations in blood flow because it also supplies the head muscles (Keith, 1969).

(2) There is no central retinal artery and vein in pigs.

(3) The major retinal vessels lie very superficially in the nerve fibre layer in contrast to the deeper location in man. This distribution may reflect the origin of the retinal vascular system in the pig from the tunica vasculosa retinae (Schultze, 1892).

(4) An avascular foveal zone is not present in the pig.

(5) The capillary nets in the pig are distinctly trilaminar in distribution, except in the peripapillary zone where four layers are present. Evidence for this in both flat preparations and thin sections is striking. Human angioarchitecture is far less distinctly laminar; in fact, Toussaint, Kuwabara, and Cogan (196I) have suggested that the radial peripapillary plexus is the only truly bidimensional layer in the human retina.

(6) The capillary plexus in man had been said to be "suspended like a hammock between its feeding arterioles and draining venules" (Toussaint and others, $196 \mathrm{I}$ ), with a greater density of nets on the venous side and frequent anastomoses between plexuses (Duke-Elder, 196I). By comparison, in the pig there is a striking association with either arterial or venous channels with less evidence of direct anastomoses between nets. The superficial vessels in the nerve fibre and outer plexiform layer are primarily arterial, whereas the deep net is chiefly venous in nature.

(7) The radial peripapillary plexus in the pig has a predominance of intra-arteriolar connections with few venular connections, in contrast to those noted in man (Henkind, $1967 \mathrm{~b}$ ).

(8) The presence of arteriolar annuli and large peripheral venous channels seen in the pig have not been noted in man. 
The features which the human and pig retinal vasculature hold in common include:

(I) A periarterial capillary-free zone.

(2) Common adventitial coats at arterio-venous crossings.

(3) Similar capillary net size. In man the average capillary net size in the deeper layer is $50 \mu$ and in the superficial layer $80 \mu$ (Michaelson, 1954). In the pig comparable figures are $48 \mu$ and $\stackrel{5}{?}$ $71 \mu$ respectively. The capillary nets related to venules are denser and a general increase in net? size, as the retinal periphery is approached, is noted in both man and pig.

(4) The retinal vessels are distributed in the strata between the inner limiting membrane and the inner nuclear layer in both man and pig.

(5) Retinal digests reveal many features shared by both man and pig. Study of the optic nerve headpoints to some similarities between the two circulations. The laminar region appears to be supplied by vessels arising from the circle of Zinn-Haller and from branches of the posterior ciliary arteries.్. In the prelaminar region, vessels derived from the choroid and laminar branches make a contribution. to the blood supply much as noted by Hayreh (1969) and Hayreh and Perkins (1969) in humansir In the pig the capillaries in the surface layer arise from smaller vessels at the disc margin originating from the prelaminar retinal vessels or from the circle of Zinn-Haller rather than recurrent branches from circumpapillary vessels as in humans (Hayreh, 1969; Hayreh and Perkins, 1969). The studieso of Dollery and others (1968) have also suggested the blood supply of the optic nerve head in this species is distinct from that of the surrounding fundus, a finding paralleled in the human and primate nerve head (Hayreh, 1969; Hayreh and Perkins, 1969). The absence of the central retinal artery and vein, the extracranial origin of the ocular supply, and the consistent presence of a circle of Zinn Haller are important differences between man and pig, thus the analogy cannot be carried too far:

A streak macula suggested in this study is a feature common to ungulates, the species too which the pig belongs (Duke-Elder, 1958). This feature is elegantly demonstrated in ox eye studied by Priestley Smith (I92I). The unusual and infrequent presence of vessels extending across from the retina on to the ciliary body or into the vitreous is mare difficult to explain. Perhaps these vessels represent an anatomical variation or could be remnants meant to supply a retinal island on the ciliary body. They certainly appear toin be embryological in origin and to be undergoing regression. Schultze (1892) described vessels in the periphery of the vitreous as well as a closely adjacent tunica vasculosat retina, but stated that no connections exist between the two. A reinvestigation of the development of the retinal vascular system in this animal might clarify the origin of these vessels.

\section{Summary}

In the pig there is no central retinal artery and major vessels lie superficially within the् retina. There is a distinct radial peripapillary plexus and peripheral venous channels Capillary nets within the retina are trilaminar with the superficial nets having chieflyg arterial and the deep net venous associations. The blood supply of the optic nerve heado and immediately surrounding retina have distinctive features described herein. Additiona $\mathrm{E}$. findings include a possible streak macula and vessels extending from the retina on to the ciliary body. The circulation of the optic nerve head and retina is compared to that of the्ठ human.

It is a pleasure to acknowledge the kind guidance and constant enthusiasm of Prof. Norman Ashton, F.R.S who suggested this project. I should also like to thank Miss E. Robins and Messrs. G. Knight and A. McNeif for their technical assistance. I am grateful to Mr. Tarrant for his beautiful drawing and to Mr. Roge Keeble for his photographic help. Miss K. O'Malley's secretarial help is greatly appreciated. 


\section{References}

Ashton, N. (1963) Brit. F. Ophthal., 47, 521

- (I966)
Ibid., 50, 283
, WARD, B., and SERPELl, G. (1954) Ibid., 38, 397 BLOODWORth, J. M. B., JR., GUtGesell, H. P., JR., and engerman, R. L. (1965) Exp. Eye Res., 4, 174 BRUNS, L. (1882) Z. vergl. Augenheilk., $\mathbf{1}, 77$

DANIEL, P. M., DAWES, J. D. K., and PrITChARD, M. M. L. (1953) Philos. Trans. B, 237, I 73

DOLlery, C. T., HENKIND, P., KOHNER, E. M., and PATERSON, J. W. (1968) Invest. Ophthal., 7, rgr

-

U.K., 85, $27 \mathrm{I}$

DUKE-ELDER, s. (1958) "System of Ophthalmology", vol. I, "The Eye in Evolution", pp. 479, 485, 498. Kimpton, London

(I96I) Idem, vol. 2 "The Anatomy of the Visual System", p. 363. Kimpton, London (I964) Idem, vol. 3, pt. 2, "Congenital Deformities", p. 264. Kimpton, London

FRANÇOIS, J., and NEETENS, A. (1962) "Comparative anatomy of the vascular supply of the eye in vertebrates", in "The Eye", ed. H. Davson, vol. I, p. 369. Academic Press, New York HAYREH, s. s. (1969) Brit. F. Ophthal., 53, 721

and PERKins, E. s. (1969) In "The William MacKenzie Centenary Symposium on the

Ocular Circulation in Health and Disease", ed. J. S. Cant, p. 7I. Kimpton, London HENKIND, P. (1967a) Invest. Ophthal., 6, 103

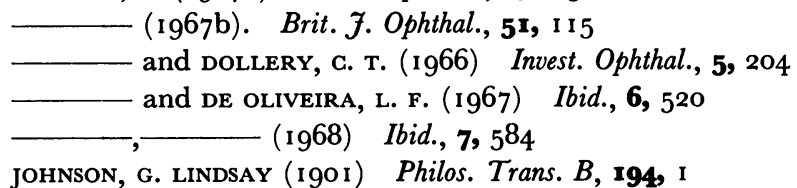

кEITH, c. G. (1969) In "The William MacKenzie Centenary Symposium on the Ocular Circulation

in Health and Disease", ed. J. S. Cant, p. 26. Kimpton, London

Kohner, e. M., dollery, c. T., henkind, p., paterson, J. W., and ramalho, P. s. (1967) Amer. $\mathcal{J}$.

Ophthal., 63, 1748

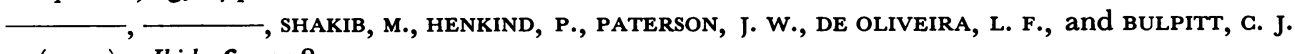

(1970) Ibid., 69, 778

LANGENBacher, L. (1880) Osterreich. Vierteljahresschrift wiss. Veterinärkunde (Wien), 53, 12 I

michaelson, I. c. (1954) "Retinal Circulation in Man and Animals", p. 102 Thomas, Spring-

field, Ill.

PRINCE, J. H., DIESEM, C. D., Eglitis, I., and RuSKell, G. L. (I960) "Anatomy and Histology of the

Eye and Orbit in Domestic Animals", p. 221. Thomas, Springfield, Ill.

schultze, o. ( 1892 ) In "Festschrift Herrn Geheimrat Albert von Koelliker zur feier seines fünfzig-

jahrigen medicinischen Doktor jubiläums gewidmet von dem Anatomischen Instit der Universität

Würzburg, Leipzig", p. i. Engelmann, Leipzig

SMITH, PRIESTLEY (192 I) Brit. F. Ophthal., 5, 385

toussaint, D., KuWABARA, T., and Cogan, D. G. (1961) Arch. Ophthal. (Chicago), 65, 575 